\title{
Vagus nerve stimulation as a potential adjuvant to behavioral therapy for autism and other neurodevelopmental disorders
}

\author{
Crystal T. Engineer ${ }^{1 *}$, Seth A. Hays ${ }^{1,2,3}$ and Michael P. Kilgard ${ }^{1,2}$
}

\begin{abstract}
Background: Many children with autism and other neurodevelopmental disorders undergo expensive, time-consuming behavioral interventions that often yield only modest improvements. The development of adjunctive interventions that can increase the benefit of rehabilitation therapies is essential in order to improve the lives of individuals with neurodevelopmental disorders.

Main text: Vagus nerve stimulation (VNS) is an FDA approved therapy that is safe and effective in reducing seizure frequency and duration in individuals with epilepsy. Individuals with neurodevelopmental disorders often exhibit decreased vagal tone, and studies indicate that VNS can be used to overcome an insufficient vagal response. Multiple studies have also documented significant improvements in quality of life after VNS therapy in individuals with neurodevelopmental disorders. Moreover, recent findings indicate that VNS significantly enhances the benefits of rehabilitative training in animal models and patients, leading to greater recovery in a variety of neurological diseases. Here, we review these findings and provide a discussion of how VNS paired with rehabilitation may yield benefits in the context of neurodevelopmental disorders.
\end{abstract}

Conclusions: VNS paired with behavioral therapy may represent a potential new approach to enhance rehabilitation that could significantly improve the outcomes of individuals with neurodevelopmental disorders.

Keywords: Vagal nerve, Plasticity, Cortex, Cortical reorganization, Autism

\section{Background}

Current therapies for autism spectrum disorders

Children with autism and other neurodevelopmental disorders often exhibit a myriad of symptoms, including social communication deficits, restricted or repetitive behaviors, epilepsy, language impairment, anxiety, developmental delays, and sensory processing problems. These symptoms arise in part from alterations in neural function. Intensive behavioral therapies can be successfully used to improve behavioral outcomes in these individuals by promoting adaptive plasticity in dysfunctional neural circuits [1-4].

A proportion of children with autism who undergo intensive interventions experience significant gains in intelligence, communication, and social skills, highlighting the importance of behavioral therapies [5-7]. However,

\footnotetext{
*Correspondence: novitski@utdallas.edu

'Texas Biomedical Device Center, The University of Texas at Dallas, 800 West Campbell Road BSB11, Richardson, TX 75080, USA

Full list of author information is available at the end of the article
}

these interventions are very time-consuming (more than $20 \mathrm{~h} /$ week), expensive (more than $\$ 30,000$ per year per child), and a substantial proportion of children fail to benefit, thereby limiting the utility of these strategies [8-11]. The development of adjunctive techniques to enhance neuroplasticity and subsequently increase the benefit of rehabilitation therapies holds promise to improve the lives of individuals with neurodevelopmental disorders.

\section{Vagus nerve stimulation therapy}

Vagus nerve stimulation (VNS) has emerged as a potential adjunctive therapy for individuals with autism. VNS is an FDA-approved therapy used to decrease the severity of treatment-resistant epilepsy and depression. An implanted pulse generator delivers intermittent trains of electrical stimulation via an electrode cuff placed around the left cervical branch of the vagus nerve. Numerous studies have documented that VNS therapy is safe and can be 
delivered to adults, as well as children as young as 6 months of age, with minimal adverse effects [12-15]. Side effects, such as coughing and hoarseness, are usually mild and temporary $[16,17]$. In addition to stimulation via an implanted device, non-invasive stimulation of either the cervical or auricular branches of the vagus nerve also may be particularly useful in patients with neurodevelopmental disorders, although considerably more testing is required to demonstrate the efficacy of non-invasive stimulation paradigms [18]. As the preponderance of studies utilize invasive VNS, this review will focus on this delivery method.

A substantial portion of epilepsy patients experience a significant reduction in both seizure frequency and severity, and it has been well-documented that responder rates increase over time [13, 19-21]. Approximately $30-40 \%$ of patients experience a $\geq 50 \%$ decrease in seizure frequency following 3-6 months of VNS therapy, while more than $60 \%$ of patients experience a $\geq 50 \%$ decrease in seizure frequency following 24 months of therapy [13, 21-23]. In addition to a reduction in seizures, significant quality of life improvements are often noted, such as increased alertness, communication, independence, memory, mood, and sleep [12, 16, 23-33]. Unlike antiepileptic drugs, VNS therapy has no reported negative effects on cognition [27]. Rather, a number of animal studies suggest that VNS may improve memory [34, 35]. In addition, VNS has antidepressant effects and enhances neurocognitive function, including executive functions and language, in patients with treatmentresistant depression [36, 37]. Moreover, a study of individuals with epilepsy documented that VNS delivered following the reading of paragraphs significantly enhanced word recognition memory [33]. Similarly, non-verbal children with epilepsy have been reported to speak their first words following VNS therapy [30]. Interestingly, these quality of life improvements are often documented to be independent of changes in seizure frequency, suggesting that multiple pathways may be engaged by VNS to yield beneficial effects [27, 31, 38].

\section{Main text \\ VNS therapy in ASD and other neurodevelopmental disorders}

A number of lines of evidence indicate that VNS may provide some symptomatic relief for individuals with autism. In many autism spectrum disorders (ASD), the parasympathetic system is dysregulated and reduced vagal tone is frequently observed [39-43]. Diminished vagal activity has been associated with both autistic behaviors and language impairment [42, 43], while higher vagal activity has been shown to predict better communication outcomes later in life [44]. VNS therapy has previously been shown to overcome an insufficient vagal response [45], suggesting that VNS therapy may be beneficial in neurodevelopmental disorders with altered parasympathetic activity.

Studies using VNS in children with both epilepsy and an autism spectrum disorder have also yielded positive results. VNS reduces seizure frequency and improves quality of life in individuals with ASD [38, 46-51]. In the largest study to date of VNS therapy in individuals with ASD, seizure reduction was similar between individuals with and without autism [46]. After 12 months of VNS therapy, $56 \%$ of individuals without autism experienced a $\geq 50 \%$ reduction in seizures, while $62 \%$ of individuals with autism experienced a $\geq 50 \%$ reduction in seizures. Individuals with and without autism exhibited similar improvements in alertness, verbal communication, memory, and school/professional achievements. However, individuals with autism also experienced a significantly greater improvement in mood following 12 months of VNS therapy compared to individuals without autism.

Another large study documented the outcomes of VNS therapy in individuals with Landau-Kleffner syndrome (acquired epileptiform aphasia) and individuals with autism [48]. Both groups experienced improvements in seizure frequency and quality of life. Among individuals with autism, a majority of patients experienced a $\geq 50 \%$ reduction in seizures and improvements in alertness, achievement, and mood.

A handful of smaller studies and case studies have also documented the positive outcomes of VNS therapy in individuals with neurodevelopmental disorders. In one striking study in girls with Rett syndrome and medically refractory epilepsy, $86 \%$ of girls had a $\geq 50 \%$ reduction in seizure frequency following 1 year of VNS therapy, and $100 \%$ of girls exhibited increased alertness [50]. A case report described an individual with Asperger syndrome and epilepsy who experienced a 69\% decrease in the number of seizures as well as an $83 \%$ decrease in seizure duration following 6 months of VNS therapy [49]. Additionally, the patient had significant improvements in mood and achievements, and a reduction of aggressive outbursts. In a separate study, children with hypothalamic hamartomas, epilepsy, and severe autistic behaviors each experienced significant behavioral improvements following VNS therapy that did not correlate with seizure control [47].

Despite the generally positive evidence of VNS on epilepsy in the context of neurodevelopmental disorders, two small studies reported no improvement in seizure control. A case report described an individual with ASD and epilepsy who experienced an initial decrease in seizure severity and duration that only lasted 6 months [38]. Despite the lack of seizure control, over the subsequent 6 months, the patient had a significant decrease in aggressive behaviors and stereotype and a significantly 
increased ability to follow directions. A separate study observed no improvement in seizure frequency in children with ASD despite mild improvement in social abilities [52]. Overall, responder rates are high considering that all patients who underwent VNS therapy had medically refractory epilepsy that was resistant to pharmacological treatment. However, there is still room for optimization of VNS therapy for epilepsy control in individuals with neurodevelopmental disorders.

\section{VNS paired with rehabilitation}

There is growing preclinical and clinical evidence that pairing bursts of VNS with specific movements or sensory events can improve rehabilitation of stroke, tinnitus, traumatic brain injury, spinal cord injury, and post-traumatic stress disorder [53]. In contrast to the open-loop delivery of 30-s long stimulation trains for epilepsy, emerging applications of VNS use short 0.5-s trains delivered coincident with specific events, such as hearing a sound or moving the hand, during a training or rehabilitative paradigm. This paradigm is based on VNS-dependent activation of plasticity-enabling neuromodulatory circuits to reinforce the neural activity associated with rehabilitation [53]. VNS pairing therapy can reorganize the brain in a manner that is both highly specific to the paired experience and long lasting. For example, pairing VNS with the presentation of a tone causes neurons in the auditory cortex to shift their preference to match the pitch of the paired tone [54, 55]. Pairing VNS with the presentation of fast or slow trains of tones increases or decreases the ability of auditory cortex to respond to rapid sounds [56]. Pairing VNS with the presentation of specific consonant sounds specifically increases the auditory cortex response strength to the paired sounds and decreases the response latency [57]. VNS pairing can also drive specific neural plasticity in motor cortex. Pairing VNS with distal forelimb movement during motor training increases the representation of the distal forelimb musculature in the motor cortex, while pairing VNS with proximal forelimb movement increases the cortical representation of the proximal forelimb $[58,59]$. Together, these findings indicate the flexibility of pairing VNS with disparate training paradigms to drive specific neural plasticity.

Based on this robust, specific enhancement of plasticity with training, several studies have tested whether VNS paired with rehabilitation may enhance the benefits of rehabilitation and support recovery in the context of neurological disease. Indeed, a number of studies in animal models and patients demonstrate that pairing VNS with sensory or motor therapy can dramatically improve functional outcomes. Pairing VNS with tones eliminated tinnitus-related behavior and normalized neural activity in a rat model of tinnitus [54]. When the same therapy was delivered in chronic tinnitus patients, it provided long-lasting improvement in tinnitus intensity and tinnitus distress, highlighting the translational potential of paired VNS [60,61]. Additional studies provide evidence that paired VNS may be useful to treat motor dysfunction resulting from neurological damage. Pairing VNS with physical rehabilitation therapy improves recovery in multiple mechanistically distinct rat models of brain injury, including ischemic stroke, intracerebral hemorrhage, and traumatic brain injury [62-66]. Other VNS paradigms highlight the potential for VNS to modulate ischemia and inflammation [67, 68]. A recent pilot in chronic stroke patients reinforces the clinical potential of VNS therapy. VNS paired with physical rehabilitation yields threefold greater improvements in upper limb function compared to rehabilitation alone [69]. Moreover, preclinical studies provide evidence that VNS paired with cognitive therapy may yield benefits. Pairing VNS with extinction therapy influences expression and activation of proteins associated with synaptic plasticity, including CaMKII, Arc, and GluN2B [70]. Consistent with these changes in plasticity-associated proteins, VNS paired with extinction therapy accelerates the extinction of a conditioned fear response in an animal model of anxiety $[45,71]$. These studies demonstrate the flexibility of VNS paired across a range of sensory, motor, and cognitive therapies and highlight its potential as a platform technology.

\section{Delivery of VNS therapy for neurodevelopmental disorders}

We propose that VNS could be paired with a variety of rehabilitative therapies targeting distinct dysfunctions to enhance adaptive neuroplasticity and improve outcomes in individuals with neurodevelopmental disorders. VNS could be incorporated into sessions of speech therapy, occupational therapy, physical therapy, or autism therapy. For VNS paired speech therapy sessions, a short burst of VNS could be delivered by a speech therapist with each attempt to speak a sound. During occupational therapy sessions, VNS could occur with each attempted movement, similar to the implementation used in stroke patients during physical rehabilitation [69]. A key benefit of VNS therapy is the ability for stimulation to be paired with well-established, existing rehabilitative interventions. The demonstrated flexibility of VNS to enhance a variety of rehabilitative training regimens holds potential to treat the many facets of dysfunction that accompany neurodevelopmental disorders, but future preclinical studies and clinical trials are necessary in order to evaluate and optimize the potential of paired VNS therapies. 


\section{Therapeutic mechanisms of VNS}

VNS therapy is believed to enhance the benefits of rehabilitation by engaging the plasticity-enabling cholinergic and noradrenergic neuromodulatory systems during training. Stimulation of the vagus nerve drives robust, phasic neural activity in the locus coeruleus, the primary source of norepinephrine in the central nervous system (CNS) [72]. Consistent with VNS-dependent engagement of the noradrenergic system, VNS increases norepinephrine levels in the hippocampus and cortex [73-75]. Additionally, VNS significantly increases levels of brain-derived neurotrophic factor (BDNF); a neurotrophin strongly linked to neural plasticity and dysregulated in autistic individuals [76-79]. Pointing to the requirement of these neuromodulatory systems, a reduction in either noradrenergic or cholinergic transmission blocks the effects of VNS in the central nervous system. Lesions of the locus coeruleus prevent VNS-dependent reduction in seizures, and antagonism of $\beta$-adrenergic receptors blocks VNS-dependent plasticity $[80,81]$. Similarly, depletion of acetylcholine prevents VNS-dependent enhancement of plasticity in motor cortex [59]. Recent clinical studies provide additional indirect evidence of the importance of these neuromodulatory systems. In a study evaluating VNS paired with tones to treat chronic tinnitus, the majority of patients that failed to benefit from VNS were on medications that interfered with neuromodulatory transmission [60]. Together, these findings highlight the importance of the cholinergic and noradrenergic systems in VNS therapy [60]. Several neurodevelopmental disorders, including Down syndrome, Rett syndrome, and Fragile X syndrome display alterations in the function of these neuromodulatory systems [82-88]. As a result of these baseline changes, VNS-dependent engagement of neuromodulatory systems may be altered in these individuals, which could in turn reduce efficacy. Alternatively, the ability to provide repeated, robust activation of these neuromodulatory systems using VNS at specific times during training exercises may promote substantial enhancement of plasticity and increase the benefits of rehabilitation.

A key component in VNS-dependent enhancement of plasticity is the close temporal association of stimulation and specific events during rehabilitation. Engagement of neuromodulatory circuits by short trains of VNS provides a precisely timed, phasic release of neuromodulators that serves to reinforce neural circuits activated during rehabilitation [72]. This temporal association between VNS and rehabilitation provides the specificity to target plasticity to particular neural circuits. Indeed, in a study evaluating VNS paired with rehabilitation to promote recovery after spinal cord injury, VNS enhanced network plasticity and synaptic connectivity specifically in neural circuits associated with control of the rehabilitated muscle groups [89]. Perhaps even more strikingly, a study in a rat model of tinnitus demonstrated that repeatedly pairing VNS with a $9 \mathrm{kHz}$ tone increased the neural response to the paired tone but not to an interleaved $4 \mathrm{kHz}$ tone presented within seconds of stimulation [54]. Consistent with the concept of precise timing mediating reinforcement, a number of studies demonstrate that an equivalent amount of VNS that is not paired with rehabilitative training fails to enhance the benefits of rehabilitation $[63,90]$. The requirement for temporal association between neural activity and VNS is consistent with studies evaluating the timing of neuromodulator release on synaptic plasticity and supports the role of phasic activation of the cholinergic and noradrenergic systems in VNSdependent benefits [91, 92]. The absence of benefits when VNS is not paired with rehabilitation indicates that VNS is likely acting to improve function by engaging neural plasticity, rather than through generalized temporally independent processes such as reduction of inflammation or neurogenesis.

In addition to activation of neuromodulatory centers in the central nervous system, VNS provides concomitant activation of the parasympathetic branch of the autonomic nervous system. The vagus nerve consists of a major portion of the descending parasympathetic fibers innervating the viscera. As a result, stimulation of the cervical vagus nerve activates these parasympathetic efferent fibers in conjunction with activation of afferent projections to CNS neuromodulatory centers (Fig. 1). Parasympathetic activation is associated with "rest-anddigest" physiological responses, and the vagus nerve carries information that mediates the transition to calm behavioral states [93, 94]. Consistent with this, a study in patients demonstrates that VNS provides a reduction in measures of anxiety [95]. The dual action of VNS in providing both a neural plasticity reinforcing stimulus through activation of ascending pathways and a calming parasympathetic input through activation of descending pathways is a unique property that may confer benefits not currently available with pharmacological interventions [96]. Drugs that activate neuromodulatory systems can enhance learning but often promote anxiety, opposing parasympathetic activation. Alternatively, anxiolytic drugs tend to interfere with plasticity and blunt the benefits of rehabilitation. Moreover, VNS-dependent parasympathetic activation may overcome altered vagal tone and autonomic dysregulation associated with a number of neurodevelopmental disorders [40-44]. At present, the ability of VNS to provide parasympathetic benefits in the context of neurodevelopmental disorders is an emerging field of study [38, 49, 51]; however, given the potential benefits of VNS, further evaluation seems warranted.

One critical step in the development of VNS-based therapy for individuals with neurodevelopmental disorders will 


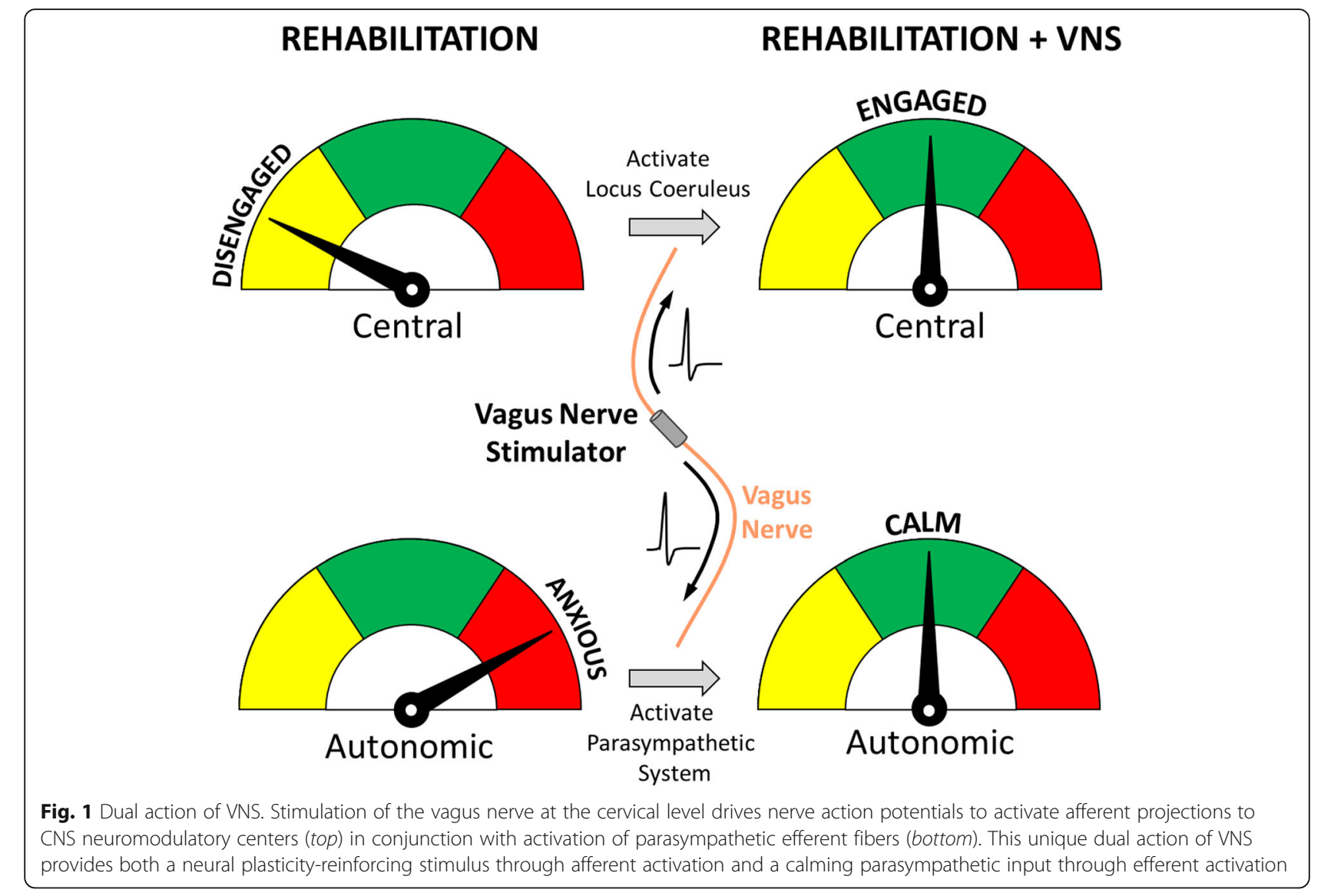

be defining the most appropriate stimulation paradigm to confer both epilepsy suppression and enhancement of rehabilitative benefits. Presently, semi-continuous $30 \mathrm{~s}$ on and 5 min off cycling stimulation has been used for epilepsy control, whereas short $0.5 \mathrm{~s}$ bursts of VNS paired with rehabilitation have been employed for targeted plasticity therapies. To date, no studies have evaluated long $30 \mathrm{~s}$ stimulation paradigms for enhancement of rehabilitation or short $0.5 \mathrm{~s}$ stimulation for epilepsy control. Clearly, if either stimulation paradigm successfully resulted in both epilepsy control and enhanced rehabilitative benefits, this stimulation paradigm should be employed. Alternatively, a hybrid combination incorporating elements of both stimulation paradigms may be most effective. For instance, individuals may receive only short bursts of VNS paired with specific events during rehabilitative sessions and subsequently receive $30 \mathrm{~s}$ on and $5 \mathrm{~min}$ off cycling stimulation when not undergoing rehabilitation. In conjunction with the potential influence of altered plasticity and neuromodulatory function, it is clear that significant efforts should be made to develop optimal VNS paradigms to provide maximal benefits for both seizure suppression and enhanced rehabilitation for individuals with neurodevelopmental disorders.

\section{Conclusions}

VNS paired with rehabilitation has emerged as an intervention that significantly improves sensory, motor, and cognitive deficits in a variety of neurological disorders. Here, we suggest that pairing VNS with rehabilitative therapy may represent a potential new approach to enhance current rehabilitative therapies and to improve the functional outcomes of individuals with neurodevelopmental disorders. Significant development of VNS therapy remains, and delivery may be limited by device cost, surgical complications, adverse effects, and the possibility that VNS-paired therapy does not enhance recovery in all patients. Future studies should evaluate both invasive and non-invasive VNS paired with rehabilitative therapies on a range of sensory, motor, and cognitive functions in a variety of neurodevelopmental disorders and focus on identifying optimal stimulation parameters to maximize therapeutic benefits.

\section{Abbreviations}

ASD: Autism spectrum disorder; CNS: Central nervous system; FXS: Fragile $X$ syndrome; VNS: Vagus nerve stimulation

Acknowledgements Not applicable. 


\section{Funding}

This research was supported by grants from the International Rett Syndrome Foundation to SAH and MPK (Grant \# 3206 and 3216) and the National Institutes of Health to SAH (Grant \# R01NS094384) and MPK (Grant \# R01DC010433, R44DC010084 \& R01NS085167). This program was supported by the Defense Advanced Research Projects Agency (DARPA) Biological Technologies Office (BTO) Electrical Prescriptions (ElectRx) program under the auspices of Dr. Doug Weber through the Space and Naval Warfare Systems Center, Pacific Cooperative Agreement No. HR0011-15-2-0017 and N66001-15-2-4057. The funders had no role in the design of the study and collection, analysis, and interpretation of data and in writing the manuscript.

\section{Availability of data and materials}

Data sharing is not applicable to this article, as no datasets were generated or analyzed.

\section{Authors' contributions}

CTE, SAH, and MPK wrote and revised the manuscript. All authors read and approved the final manuscript.

\section{Competing interests}

MPK is a paid consultant for and shareholder in MicroTransponder Inc., which is pursuing VNS as a therapy for tinnitus and stroke. MPK has several patents related to VNS. All other authors declare that they have no competing interests.

\section{Consent for publication}

Not applicable.

\section{Ethics approval and consent to participate} Not applicable.

\section{Publisher's Note}

Springer Nature remains neutral with regard to jurisdictional claims in published maps and institutional affiliations.

\section{Author details}

${ }^{1}$ Texas Biomedical Device Center, The University of Texas at Dallas, 800 West Campbell Road BSB11, Richardson, TX 75080, USA. ${ }^{2}$ School of Behavioral and Brain Sciences, The University of Texas at Dallas, 800 West Campbell Road BSB11, Richardson, TX 75080, USA. ${ }^{3}$ Erik Jonsson School of Engineering and Computer Science, The University of Texas at Dallas, 800 West Campbell Road BSB11, Richardson, TX 75080, USA.

\section{Received: 20 December 2016 Accepted: 11 May 2017}

Published online: 04 July 2017

\section{References}

1. Dawson G, Rogers S, Munson J, Smith M, Winter J, Greenson J, et al. Randomized, controlled trial of an intervention for toddlers with autism: the Early Start Denver Model. Pediatrics. 2010;125:e17-23.

2. Dawson G, Jones EJH, Merkle K, Venema K, Lowy R, Faja S, et al. Early behavioral intervention is associated with normalized brain activity in young children with autism. J Am Acad Child Adolesc Psychiatry. 2012;51:1150-9. Elsevier Inc.

3. Russo NM, Hornickel J, Nicol T, Zecker S, Kraus N. Biological changes in auditory function following training in children with autism spectrum disorders. Behav Brain Funct. 2010;6:60.

4. McEachin JJ, Smith T, Lovaas Ol. Long-term outcome for children with autism who received early intensive behavioral treatment. Am J Ment Retard. 1993;97:359. 72-91.

5. Klintwall L, Eldevik S, Eikeseth S. Narrowing the gap: effects of intervention on developmental trajectories in autism. Autism. 2015;19:53-63.

6. Lovaas OI. Behavioral treatment and normal educational and intellectual functioning in young autistic children. J Consult Clin Psychol. 1987;55:3-9.

7. Kuhl PK, Coffey-Corina S, Padden D, Munson J, Estes A, Dawson G. Brain responses to words in 2-year-olds with autism predict developmental outcomes at age 6. PLoS One. 2013;8, e64967.

8. Ouyang L, Grosse SD, Riley C, Bolen J, Bishop E, Raspa M, et al. A comparison of family financial and employment impacts of fragile $X$ syndrome, autism spectrum disorders, and intellectual disability. Res Dev Disabil. 2014;35:1518-27.

9. Shattuck PT, Roux AM. Autism: moving toward an innovation and investment mindset. JAMA Pediatr. 2014:9-10.

10. Horlin C, Falkmer M, Parsons R, Albrecht M, Falkmer T. The cost of autism spectrum disorders. PLoS One. 2014;9, e106552.

11. Buescher AVS, Cidav Z, Knapp M, Mandell DS. Costs of autism spectrum disorders in the United Kingdom and the United States. JAMA Pediatr. 2014;19104:1-8.

12. Zamponi N, Rychlicki F, Corpaci L, Cesaroni E, Trignani R. Vagus nerve stimulation (VNS) is effective in treating catastrophic 1 epilepsy in very young children. Neurosurg Rev. 2008;31:291-7.

13. Orosz I, McCormick D, Zamponi N, Varadkar S, Feucht M, Parain D, et al. Vagus nerve stimulation for drug-resistant epilepsy: a European long-term study up to 24 months in 347 children. Epilepsia. 2014;55:1576-84.

14. Koo B, Ham SD, Sood S, Tarver B. Human vagus nerve electrophysiology: a guide to vagus nerve stimulation parameters. J Clin Neurophysiol. 2001;18:429-33.

15. Hauptman JS, Mathern GW. Vagal nerve stimulation for pharmacoresistant epilepsy in children. Surg Neurol Int. 2012;3:S269-74.

16. Terra VC, Furlanetti LL, Nunes AA, Thomé U, Nisyiama MA, Sakamoto AC, et al. Vagus nerve stimulation in pediatric patients: is it really worthwhile? Epilepsy Behav. 2014;31:329-33. Elsevier Inc.

17. Alonso-Vanegas MA, Austria-Velásquez J, López-Gómez M, Brust-Mascher E. Chronic intermittent vagal nerve stimulation in the treatment of refractory epilepsy: experience in Mexico with 35 cases. Cirugía y Cir. 2010;78:15-23. 24.

18. Ben-Menachem E, Revesz D, Simon BJ, Silberstein S. Surgically implanted and non-invasive vagus nerve stimulation: a review of efficacy, safety and tolerability. Eur J Neurol. 2015;22:1260-8.

19. Englot DJ, Rolston JD, Wright CW, Hassnain KH, Chang EF. Rates and predictors of seizure freedom with vagus nerve stimulation for intractable epilepsy. Neurosurgery. 2016;79:345-53.

20. Kamath MV, Thomson MS, Gaitonde S, Upton A. Longer-term effects of implanted vagal nerve stimulation. J Long Term Eff Med Implants. 2010; 20:251-67.

21. Rychlicki F, Zamponi N, Trignani R, Ricciuti RA, lacoangeli M, Scerrati M. Vagus nerve stimulation: clinical experience in drug-resistant pediatric epileptic patients. Seizure. 2006;15:483-90.

22. Patwardhan RV, Stong B, Bebin EM, Mathisen J, Grabb PA. Efficacy of vagal nerve stimulation in children with medically refractory epilepsy. Neurosurgery. 2000;47:1353. 7-8.

23. Nagarajan L, Walsh P, Gregory P, Lee M. VNS therapy in clinical practice in children with refractory epilepsy. Acta Neurol Scand. 2002;105:13-7.

24. Shahwan A, Bailey C, Maxiner W, Harvey AS. Vagus nerve stimulation for refractory epilepsy in children: more to VNS than seizure frequency reduction. Epilepsia. 2009;50:1220-8.

25. Parker AP, Polkey CE, Binnie CD, Madigan C, Ferrie CD, Robinson RO. Vagal nerve stimulation in epileptic encephalopathies. Pediatrics. 1999;103:778-82.

26. Parain D, Penniello MJ, Berquen P, Delangre T, Billard C, Murphy JV. Vagal nerve stimulation in tuberous sclerosis complex patients. Pediatr Neurol. 2001;25:213-6.

27. Klinkenberg S, Van Den Bosch CNCJ, Majoie HJM, Aalbers MW, Leenen L, Hendriksen J, et al. Behavioural and cognitive effects during vagus nerve stimulation in children with intractable epilepsy-A randomized controlled trial. Eur J Paediatr Neurol. 2013;17:82-90. Elsevier Ltd.

28. Helmers SL, Wheless JW, Frost M, Gates J, Levisohn P, Tardo C, et al. Vagus nerve stimulation therapy in pediatric patients with refractory epilepsy: retrospective study. J Child Neurol. 2001;16:843-8.

29. Hallböök T, Lundgren J, Köhler S, Blennow G, Strömblad L-G, Rosén I. Beneficial effects on sleep of vagus nerve stimulation in children with therapy resistant epilepsy. Eur J Paediatr Neurol. 2005;9:399-407.

30. Grill MF, Ng Y. Dramatic first words spoken in 2 children after vagus nerve stimulation. Semin Pediatr Neurol. 2010;17:54-7. Elsevier Inc.

31. Aldenkamp AP, Van de Veerdonk SH, Majoie HJ, Berfelo MW, Evers SM, Kessels AG, et al. Effects of 6 months of treatment with vagus nerve stimulation on behavior in children with lennox-gastaut syndrome in an open clinical and nonrandomized study. Epilepsy Behav. 2001;2:343-50.

32. Galli R, Bonanni E, Pizzanelli C, Maestri M, Lutzemberger L, Giorgi FS, et al. Daytime vigilance and quality of life in epileptic patients treated with vagus nerve stimulation. Epilepsy Behav. 2003:4:185-91. 
33. Clark KB, Naritoku DK, Smith DC, Browning RA, Jensen RA. Enhanced recognition memory following vagus nerve stimulation in human subjects. Nat Neurosci. 1999;2:94-8.

34. Clark KB, Krahl SE, Smith DC, Jensen RA. Post-training unilateral vagal stimulation enhances retention performance in the rat. Neurobiol Learn Mem. 1995;63:213-6.

35. Clark KB, Smith DC, Hassert DL, Browning RA, Naritoku DK, Jensen RA. Posttraining electrical stimulation of vagal afferents with concomitant vagal efferent inactivation enhances memory storage processes in the rat. Neurobiol Learn Mem. 1998;70:364-73.

36. Sackeim HA, Keilp JG, Rush AJ, George MS, Marangell LB, Dormer JS, et al. The effects of vagus nerve stimulation on cognitive performance in patients with treatment-resistant depression. Neuropsychiatry Neuropsychol Behav Neurol. 2001;14:53-62.

37. Nahas Z, Marangell LB, Husain MM, Rush AJ, Sackeim HA, Lisanby SH, et al. Two-year outcome of vagus nerve stimulation (VNS) for treatment of major depressive episodes. J Clin Psychiatry. 2005;66:1097-104.

38. Hull MM, Madhavan D, Zaroff CM. Autistic spectrum disorder, epilepsy, and vagus nerve stimulation. Childs Nerv Syst. 2015;31:1377-85.

39. Cheshire WP. Highlights in clinical autonomic neuroscience: new insights into autonomic dysfunction in autism. Auton Neurosci. 2012;171:4-7. Elsevier B.V.

40. Cohen S, Masyn K, Mastergeorge A, Hessl D. Psychophysiological responses to emotional stimuli in children and adolescents with autism and fragile $X$ syndrome. J Clin Child Adolesc Psychol. 2015;44:250-63.

41. Hall SS, Lightbody AA, Huffman LC, Lazzeroni LC, Reiss AL. Physiological correlates of social avoidance behavior in children and adolescents with fragile x syndrome. J Am Acad Child Adolesc Psychiatry. 2009;48:320-9.

42. Klusek J, Martin GE, Losh M. Physiological arousal in autism and fragile X syndrome: group comparisons and links with pragmatic language. Am J Intellect Dev Disabil. 2013;118:475-95.

43. Roberts JE, Tonnsen B, Robinson A, Shinkareva SV. Heart activity and autistic behavior in infants and toddlers with fragile $X$ syndrome. Am J Intellect Dev Disabil. 2012;117:90-102.

44. Watson LR, Baranek GT, Roberts JE, David FJ, Perryman TY. Behavioral and physiological responses to child-directed speech as predictors of communication outcomes in children with autism spectrum disorders. J Speech, Lang Hear Res. 2010;53:1052-64.

45. Peña DF, Childs JE, Willett S, Vital A, McIntyre CK, Kroener S. Vagus nerve stimulation enhances extinction of conditioned fear and modulates plasticity in the pathway from the ventromedial prefrontal cortex to the amygdala. Front Behav Neurosci. 2014;8:327.

46. Levy ML, Levy KM, Hoff D, Amar AP, Park MS, Conklin JM, et al. Vagus nerve stimulation therapy in patients with autism spectrum disorder and intractable epilepsy: results from the vagus nerve stimulation therapy patient outcome registry. J Neurosurg Pediatr. 2010;5:595-602.

47. Murphy JV, Wheless JW, Schmoll CM. Left vagal nerve stimulation in six patients with hypothalamic hamartomas. Pediatr Neurol. 2000;23:167-8.

48. Park YD. The effects of vagus nerve stimulation therapy on patients with intractable seizures and either Landau-Kleffner syndrome or autism. Epilepsy Behav. 2003:4:286-90.

49. Warwick TC, Griffith J, Reyes B, Legesse B, Evans M. Effects of vagus nerve stimulation in a patient with temporal lobe epilepsy and Asperger syndrome: case report and review of the literature. Epilepsy Behav. 2007;10:344-7.

50. Wilfong AA, Schultz RJ. Vagus nerve stimulation for treatment of epilepsy in Rett syndrome. Dev Med Child Neurol. 2006:48:683-6.

51. Manning KE, McAllister CJ, Ring HA, Finer N, Kelly CL, Sylvester KP, et al. Novel insights into maladaptive behaviours in Prader-Willi syndrome: serendipitous findings from an open trial of vagus nerve stimulation. J Intellect Disabil Res. 2016;60:149-55.

52. Danielsson S, Viggedal G, Gillberg C, Olsson I. Lack of effects of vagus nerve stimulation on drug-resistant epilepsy in eight pediatric patients with autism spectrum disorders: a prospective 2-year follow-up study. Epilepsy Behav. 2008;12:298-304.

53. Hays SA. Enhancing rehabilitative therapies with vagus nerve stimulation. Neurotherapeutics. 2016;13:382-94.

54. Engineer ND, Riley JR, Seale JD, Vrana WA, Shetake JA, Sudanagunta SP, et al. Reversing pathological neural activity using targeted plasticity. Nature. 2011;470:101-4. Nature Publishing Group.

55. Borland MS, Vrana WA, Moreno NA, Fogarty EA, Buell EP, Sharma P, et al. Cortical map plasticity as a function of vagus nerve stimulation intensity. Brain Stimul. 2015;9:117-23.
56. Shetake JA, Engineer ND, Vrana WA, Wolf JT, Kilgard MP. Pairing tone trains with vagus nerve stimulation induces temporal plasticity in auditory cortex. Exp Neurol. 2012;233:342-9. Elsevier Inc.

57. Engineer $C T$, Engineer ND, Riley JR, Seale JD, Kilgard MP. Pairing speech sounds with vagus nerve stimulation drives stimulus-specific cortical plasticity. Brain Stimul. 2015;8:637-44.

58. Porter BA, Khodaparast N, Fayyaz T, Cheung RJ, Ahmed SS, Vrana WA, et al. Repeatedly pairing vagus nerve stimulation with a movement reorganizes primary motor cortex. Cereb Cortex. 2012;22:2365-74.

59. Hulsey DR, Hays SA, Khodaparast N, Ruiz A, Das P, Rennaker RL, et al. Reorganization of motor cortex by vagus nerve stimulation requires cholinergic innervation. Brain Stimul. 2016;9:174-81.

60. De Ridder D, Vanneste S, Engineer ND, Kilgard MP. Safety and efficacy of vagus nerve stimulation paired with tones for the treatment of tinnitus: a case series. Neuromodulation. 2014;17:170-9.

61. De Ridder D, Kilgard M, Engineer N, Vanneste S. Placebo-controlled vagus nerve stimulation paired with tones in a patient with refractory tinnitus: a case report. Otol Neurotol. 2015;36:575-80.

62. Hays SA, Khodaparast N, Hulsey DR, Ruiz A, Sloan AM, Rennaker RL, et al. Vagus nerve stimulation during rehabilitative training improves functional recovery after intracerebral hemorrhage. Stroke. 2014;45:3097-100.

63. Hays SA, Khodaparast N, Ruiz A, Sloan AM, Hulsey DR, Rennaker RL, et al. The timing and amount of vagus nerve stimulation during rehabilitative training affect poststroke recovery of forelimb strength. Neuroreport. 2014;25:676-82.

64. Khodaparast N, Hays SA, Sloan AM, Hulsey DR, Ruiz A, Pantoja M, et al. Vagus nerve stimulation during rehabilitative training improves forelimb strength following ischemic stroke. Neurobiol Dis. 2013;60:80-8.

65. Khodaparast N, Hays SA, Sloan AM, Fayyaz T, Hulsey DR, Rennaker RL, et al. Vagus nerve stimulation delivered during motor rehabilitation improves recovery in a rat model of stroke. Neurorehabil Neural Repair. 2014;28:698-706

66. Pruitt DT, Schmid AN, Kim LJ, Abe CM, Trieu JL, Choua C, et al. Vagus nerve stimulation delivered with motor training enhances recovery of function after traumatic brain injury. J Neurotrauma. 2016;33:871-9.

67. Ay I, Lu J, Ay H, Gregory SA. Vagus nerve stimulation reduces infarct size in rat focal cerebral ischemia. Neurosci Lett. 2009;459:147-51.

68. Borovikova LV, Ivanova S, Zhang M, Yang H, Botchkina Gl, Watkins LR, et al. Vagus nerve stimulation attenuates the systemic inflammatory response to endotoxin. Nature. 2000:405:458-62.

69. Dawson J, Pierce D, Dixit A, Kimberley TJ, Robertson M, Tarver B, et al. Safety, feasibility, and efficacy of vagus nerve stimulation paired with upperlimb rehabilitation after ischemic stroke. Stroke. 2016:47:143-50.

70. Alvarez-Dieppa AC, Griffin K, Cavalier S, Mclntyre CK. Vagus nerve stimulation enhances extinction of conditioned fear in rats and modulates arc protein, CaMKII, and GluN2B-containing NMDA receptors in the basolateral amygdala. Neural Plast. 2016;2016:4273280.

71. Peña DF, Engineer ND, Mclntyre CK. Rapid remission of conditioned fear expression with extinction training paired with vagus nerve stimulation. Biol Psychiatry. 2013;73:1071-7.

72. Hulsey DR, Riley JR, Loerwald KW, Rennaker RL, Kilgard MP, Hays SA Parametric characterization of neural activity in the locus coeruleus in response to vagus nerve stimulation. Exp Neurol. 2017:289:21-30.

73. Hassert DL, Miyashita T, Williams CL. The effects of peripheral vagal nerve stimulation at a memory-modulating intensity on norepinephrine output in the basolateral amygdala. Behav Neurosci. 2004;118:79-88.

74. Roosevelt RW, Smith DC, Clough RW, Jensen RA, Browning RA. Increased extracellular concentrations of norepinephrine in cortex and hippocampus following vagus nerve stimulation in the rat. Brain Res. 2006;1119:124-32.

75. Follesa P, Biggio F, Gorini G, Caria S, Talani G, Dazzi L, et al. Vagus nerve stimulation increases norepinephrine concentration and the gene expression of BDNF and bFGF in the rat brain. Brain Res. 2007;1179:28-34.

76. Miyazaki K, Narita N, Sakuta R, Miyahara T, Naruse H, Okado N, et al. Serum neurotrophin concentrations in autism and mental retardation: a pilot study. Brain Dev. 2004;26:292-5.

77. Correia CT, Coutinho AM, Sequeira AF, Sousa IG, Lourenço Venda L, Almeida JP, et al. Increased BDNF levels and NTRK2 gene association suggest a disruption of BDNF/TrkB signaling in autism. Genes Brain Behav. 2010;9:841-8.

78. Ricci S, Businaro R, Ippoliti F, Lo Vasco VR, Massoni F, Onofri E, et al. Altered cytokine and BDNF levels in autism spectrum disorder. Neurotox Res. 2013;24:491-501. 
79. Schinder AF, Poo M. The neurotrophin hypothesis for synaptic plasticity. Trends Neurosci. 2000;23:639-45.

80. Shen H, Fuchino Y, Miyamoto D, Nomura H, Matsuki N. Vagus nerve stimulation enhances perforant path-CA3 synaptic transmission via the activation of $\beta$-adrenergic receptors and the locus coeruleus. Int J Neuropsychopharmacol. 2012;15:523-30.

81. Krahl SE, Clark KB, Smith DC, Browning RA. Locus coeruleus lesions suppress the seizure-attenuating effects of vagus nerve stimulation. Epilepsia. 1998;39:709-14.

82. Yates CM, Simpson J, Gordon A, Maloney AF, Allison Y, Ritchie IM, et al. Catecholamines and cholinergic enzymes in pre-senile and senile Alzheimertype dementia and Down's syndrome. Brain Res. 1983;280:119-26.

83. German DC, Manaye KF, White CL, Woodward DJ, McIntire DD, Smith WK, et al. Disease-specific patterns of locus coeruleus cell loss. Ann Neurol. 1992;32: 667-76.

84. Taneja P, Ogier M, Brooks-Harris G, Schmid DA, Katz DM, Nelson SB. Pathophysiology of locus ceruleus neurons in a mouse model of Rett syndrome. J Neurosci. 2009;29:12187-95.

85. Wu Y, Zhong W, Cui N, Johnson CM, Xing H, Zhang S, et al. Characterization of Rett Syndrome-like phenotypes in Mecp2-knockout rats. J Neurodev Disord. 2016;8:23.

86. Volk $L$, Pfeiffer BE, Gibson JR, Huber KM. Multiple Gq-coupled receptors converge on a common protein synthesis-dependent long-term depression that is affected in fragile $X$ syndrome mental retardation. J Neurosci. 2007; 27:11624-34.

87. Roberts JE, Boccia ML, Bailey DB, Hatton DD, Skinner M. Cardiovascular indices of physiological arousal in boys with fragile $\mathrm{X}$ syndrome. Dev Psychobiol. 2001;39:107-23.

88. Figueroa A, Collier SR, Baynard T, Giannopoulou I, Goulopoulou S, Fernhall B. Impaired vagal modulation of heart rate in individuals with Down syndrome. Clin Auton Res. 2005;15:45-50.

89. Ganzer P, Meyers E, Solorzano B, Adcock K, Robertson N, James J, et al. Enhancing plasticity and recovery following spinal cord injury. Soc Neurosci Annu Meet. 2016. p. nr 59.13.

90. Khodaparast N, Kilgard MP, Casavant R, Ruiz A, Qureshi I, Ganzer PD, et al. Vagus nerve stimulation during rehabilitative training improves forelimb recovery after chronic ischemic stroke in rats. Neurorehabil Neural Repair. 2016;30:676-84

91. He K, Huertas M, Hong SZ, Tie X, Hell JW, Shouval H, et al. Distinct eligibility traces for LTP and LTD in cortical synapses. Neuron. 2015;88: 528-38. Elsevier Inc

92. Yagishita S, Hayashi-Takagi A, Ellis-Davies GCR, Urakubo H, Ishii S, Kasai H. A critical time window for dopamine actions on the structural plasticity of dendritic spines. Science. 2014;345:1616-20.

93. Zagon A. Does the vagus nerve mediate the sixth sense? Trends Neurosci. 2001;24:671-3.

94. Porges S. The vagus: a mediator of behavioral and physiologic features associated with autism. In: Bauman M, Kemper T, editors. Neurobiol. autism. 2nd ed. Baltimore: The Johns Hopkins University Press; 2005. p. 65-78.

95. George MS, Ward HE, Ninan PT, Pollack M, Nahas Z, Anderson B, et al. A pilot study of vagus nerve stimulation (VNS) for treatment-resistant anxiety disorders. Brain Stimul. 2008;1:112-21.

96. Fanselow MS. Fear and anxiety take a double hit from vagal nerve stimulation. Biol Psychiatry. 2013;73:1043-4.

\section{Submit your next manuscript to BioMed Central and we will help you at every step:}

- We accept pre-submission inquiries

- Our selector tool helps you to find the most relevant journal

- We provide round the clock customer support

- Convenient online submission

- Thorough peer review

- Inclusion in PubMed and all major indexing services

- Maximum visibility for your research

Submit your manuscript at www.biomedcentral.com/submit

CBiomed Central 